\title{
The Remote Village Square: Exploring The Potential Of Glocal Broadcasting Over The Internet
}

Elad Harison, Shenkar College of Engineering and Design, Israel Ofer Barkai, Shamoon College of Engineering, Israel

\begin{abstract}
The growing trends of immigration and international population movements worldwide emphasize issues of the naturalization efforts of immigrants in their new nation, while sustaining their ties to their homeland via the Internet. The paper analyzes the potential of Internet-based regional broadcasting to enhance the attachment of communities of immigrants to their regional identity and culture. A case study conducted at the Dutch Omrop Fryslân radio broadcasting station, and within the communities of its listeners inland and abroad, provides useful insights into the potential role of regional broadcasting as a glocal (i.e. both locally related and globally transmitted) medium of communication in the Internet era. Finally, conclusions on the role of regional public broadcasting stations that transmit via the Internet as a bridgehead to communities of immigrants, and on the glocal nature of their contents, are drawn.
\end{abstract}

Keywords: Radio; Internet; Public Broadcasting; Regional Broadcasting; Glocal

\section{INTRODUCTION}

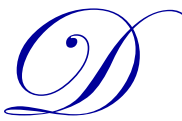

ramatic economic changes, shifts in personal status, and professional opportunities are fostered both by changes in the world economy and by the global communication platforms enabled by Internet connectivity (Docquier, Rapoport \& Salomone, 2012). Very often, nations are willing to attract professional and educated labor to develop different economic and industrial sectors, or to fill in for lack of professionals in particular fields (see, for example, Chen, Auerbach, Muench, Curry \& Bradley, 2013). These phenomena, among other social changes, generate exponentially growing trends of immigration and international population movements worldwide.

In parallel to naturalization efforts in their new lands, immigrants usually aim at preserving cultural contacts with their homelands, and aspire to preserve cultural and linguistic ties among their offspring (Elias \& Lemish, 2011; Toivanen \& Kivisto, 2014). These efforts attempt to secure the social structures imported from the homeland against disintegration, due to the phenomenon of anomie: transition from domestic communities to foreign land and society that significantly modify the social links and structures and the sense of community among immigrants (Merton, 1938; For a recent study of anomie among American Internet users see Rusciano, 2014). In addition, in their attempts to educate and to expose the second and third generations to the culture of the homeland, parents seek new ways to continuously provide content and education that are based on their homeland culture and idioms (Zhou and Cai, 2002; Elias, 2013).

In this respect, one should bear in mind that each cultural group has its own characteristics, such as language, values, norms and symbols, among many others, which can reflect on the potential of utilizing different communication channels, including Internet access. ${ }^{1}$ Culture is affected by the location of both citizens and

\footnotetext{
${ }^{1}$ For example, members of orthodox Jewish communities are forbidden from browsing the Internet, due to potential exposure to non-pious contents.
} 
immigrants in five different ways, which also determine the manners of internal organization of communities and how their members interact:

- $\quad$ Power distance - The degree of inequality common in a country

- $\quad$ Uncertainty avoidance - The degree to which persons prefer structured situations whereby rules dictate how situations should be handled

- Individualism - The degree to which persons within a country act as individuals, as opposed to acting as members of a group

- $\quad$ Masculinity - The degree to which values like assertiveness, performance, success and competition are valued above other values, such as maintaining warm personal relationships, service, care for the weak, and solidarity

- $\quad$ Long term - The degree to which people tend to prefer values oriented to the future, such as saving and perseverance, over values based on the past and the present, such as respect for tradition and fulfillment of social obligations (Hofstede, 1994).

Interestingly, the adoption of homeland culture and languages is not enforced by elders, but rather is willingly adopted by the younger generations (Soehl \& Waldinger, 2012; Yan, Lam, \& Lauer, 2014). Additionally, most adopters of Internet-based broadcasting channels are usually characterized as the "Net generation", born since 1977 into an environment populated with personal computers, video games and Internet information sources and communication platforms, and thereby tending to be globally oriented and technological savvy (Leung, 2004).

As seen earlier, the potential of a program can be determined by the online success per program type (Loebbecke, Powell \& Trillingh, 1998). The type of a broadcasting program predicts its success and the popularity of the website that supports it. Lin (2008) shows that contemporary content leads in the interests of media consumers. Ninety-three percent of the sampled population watched news webcasts. Following news, the most popular programs were sports and weather. However, a large proportion of the respondents were also interested in non-contemporary programs, including sitcoms and dramas.

Whether the broadcasting organization is commercial, and thereby driven by generation of revenues, or publicly-funded, and thereupon bound to comply with the preferences of the public that it serves, these findings assist in defining the orientation of the contents that it should broadcast, with a strong adherence to news-based programs and coverage of contemporary events.

The use of Internet-based broadcasting methods, such as live streaming and podcasts of radio shows, enables media consumers to listen to and watch programs without any geographical restrictions. Additionally, when media content is stored and organized in online accessible repositories, the limitations of different time zones are removed. Thereupon, programs broadcast over the Internet have become very popular within communities of immigrants, who can familiarize themselves with the ongoing happenings in their homelands. This platform for radio and video broadcasting thereby provides a truly glocal experience, in which listeners are distributed worldwide in different nations and among many different cultures, while at the same being able to familiarize themselves with events in geographically remote regions in which they are interested.

\section{CONCEPTUAL FRAMEWORK AND RESEARCH METHOD}

The paper analyzes the potential of regional broadcasting that appeals to remote communities of immigrants and residents in terms of sustaining the cultural and linguistic links between these communities and their historical homelands, thus enhancing their attachment to their regional identity despite residing abroad.

The issues associated with the national and the regional identities of communities of immigrants are of a special interest for this study: Can cross-border media broadcasting strengthen the inherent perception of immigrants towards their former regional identities, despite the geographical distance from their homelands? Can Internet-based radio (or other media) facilitate interest among immigrants about the events and developments in their region? Can interest in former homelands and regions diffuse into the immigrants' offspring? 
The paper addresses these questions by elaborating the findings of a case study conducted within the Dutch Omrop Fryslân radio broadcasting station, and within the communities of its listeners inland and abroad. The case offers insights into the habits and the various characteristics of the cultural and linguistic links of communities of immigrants, and reviews the different types of regional media and updates that immigrants consume - similar to the Dutch residents that the radio broadcasts originally target — hence forming a strong glocal context via Internet-based media.

\section{FOSTERING THE GLOCAL LINKS ABROAD: THE CASE OF THE OMROP FRYSLÂN RADIO BROADCASTING STATION}

\subsection{Background}

The Dutch province of Fryslân is located in the north of the Netherlands. From the social and cultural standpoints, Fryslân is often seen as different from the rest of the Netherlands, the most notable difference being that the Frisian language, rather than the Dutch language, is spoken by a significant part of the Frisian population.

Omrop Fryslân is the only Frisian-speaking broadcaster among the 13 public broadcasting organizations in the Netherlands. It operates radio and television broadcasts, as well as a website in the Frisian language.

Omrop Fryslân started broadcasting in 1994, after government funding was allocated to public television organizations, initially producing and broadcasting two hours per day. Today, Omrop Fryslân broadcasts morningto-midnight programs, which are repeated during the night-time. Radio broadcasts begin in the early morning and continue into the late night hours. Its website features the latest regional news, as well as information about programs.

Omrop Fryslân has 140 direct employees and approximately 200 freelance employees, and most of the television and radio programs are produced in-house. Only a minority of content is purchased from external production companies, as external materials are usually produced in English or Dutch, and require extensive adaptation to provide them in the Frisian language.

Omrop Fryslân's mission is to be the leading source of information in the province of Fryslân. It aims at fulfilling it by conducting the following types of programs: local, regional and national news coverage; entertainment programs; educational programs; programs featuring popular regional and cultural events; and emergency broadcasting.

A debate about whether the new website of Omrop Fryslân should be launched solely in the Frisian language, or should also be translated into Dutch, surfaced at the beginning of 2007. Advocates of a Dutch version of the website claimed that it could foster the growth of its use by non-Frisian speakers; while opponents highlighted the importance of the cultural and linguistic uniqueness of Omrop Fryslân among the Frisian population.

While the new version of the broadcaster's website draws more visitors than the old version, and offers more opportunities to consume media, the organization decided to resume a "purist" strategy that differentiates it as a unique regional media supplier, hence providing all contents only in Frisian without translation into Dutch. Moreover, as the journalists of Omrop Fryslân report only local news from the province of Fryslân, in which Frisian is the main language, and national and international news hardly ever appear in the website, in television or in radio programs, translation of contents to the Dutch language would put an extra financial and operational burden on the broadcaster without increasing its reach to broader audiences.

Finally, Omrop Fryslân's management decided to sustain its Frisian-only policy for its Internet presence as well. However, this debate has sparked a deeper controversy: What is the mission of Omrop Fryslân as a public broadcasting organization operating for a national minority? Is it simply informing the citizens of Fryslân about events and news in their province; or is it a broader mission of promoting the Frisian culture and the use of the Frisian language, and in the broadest context, strengthening the Frisian identity? 


\subsection{The Dutch Broadcasting Market and Regulation}

The regulative Dutch broadcasting environment is open to both public and commercial broadcasters, and aims at facilitating initiation of new public or commercial broadcasting organizations with relative ease. Dutch law obliges cable companies to transmit the three public TV channels and, in addition, to provide additional channels of interest to their audience. Public broadcasters can be classified into three major groups according to their objectives: broadcasters with a religious background and aims; member-based broadcasters; and specialized broadcasting organizations (mostly stations of political parties). The state allocates radio frequencies that are available to public broadcasters. National broadcasters share six radio frequencies, while regional and local broadcasters have their own domestic frequencies. For example, religious broadcasters receive broadcasting time from public channels, as they broadcast religious contents in a free-to-air mode, and do not base their operations on member subscriptions. In total, the Dutch religious broadcasters receive funding to produce and broadcast approximately 400 hours of television airtime, and over 1,000 hours of radio programs.

Commercial broadcasting in the Netherlands began with the first commercial Dutch television station in 1989. Since then, many more broadcasters have entered the Dutch television market, including cable companies. The national regulators appoint regional advisory boards that advise about a minimal package of freely distributed channels, while commercial channels are at risk of deletion when the advisory board deems them unwanted-for example due to infringement of regulatory guidelines. Although the first non-public Dutch radio broadcaster started in 1924, the Dutch government did not allow commercial broadcasting until the 1980s. Before then, Dutch commercial radio stations broadcast from ships in the North Sea under a foreign flag, so that Dutch broadcasting law did not apply. In the early 1990s European law made commercial radio in the Netherlands legal by overruling Dutch law. Since then, numerous Dutch commercial radio broadcasters have been founded, and since 2003 the Dutch government auctions radio frequencies to any commercial broadcaster, with each station entitled to broadcast a particular genre of content.

\section{ADOPTING THE SENSE OF COMMUNITY: FROM FOCUS ON GLOCAL CONTENT TOWARDS MULTIPLE BUSINESS FOCAL POINTS}

The regulative and commercial media landscape in which broadcasting organizations operate, as well as the internal attributes and organization of each broadcaster, assist in shaping their strategies, business activities, and selected genres and contents. The performance of organizations and their strategic directions are affected by the economy, by regulative guidelines and by the preferences and technological use of their audience. In addition, the inherent properties of each broadcaster influence its strategy, technology adoption and business strategy in terms of its core products and capabilities (e.g. news coverage, sport programs, etc.), the relations between air and online broadcasting, and the propensity to implement new technologies that explore the media interfaces between them and the branding of the broadcaster, and its scope of activities and contents (Chan-Olmsted and Ha, 2003; Chan-Olmsted and Kan, 2003; Doyle, 2010).

Different models of media broadcasting suggested that media organizations can serve the needs and preferences of their audiences in four major ways:

- Revenue focus, which is popular in the commercial broadcasting market, aims at generating maximal income to the broadcasting organization via development of advertising, paying subscribers and consumers of paid services (e.g. purchases of syndicated materials or development of online merchandizing).

- Cost focus, which is utilized by media organizations with stable audiences and financial support, addresses the structure of expenses and aims at reducing the costs of broadcasting by enhancing the efficiency of the organization. The cost focus is particularly relevant for broadcasting organizations funded by the public that confront fierce competition from commercial broadcasters, or undergo substantial budget cuts.

- $\quad$ Support focus suggests that the major focal point of the media organization should address the community in which it operates and its unique needs, hence fulfilling its objective as a provider of societal and cultural services to the community (either local or national) over the airwaves. Religious stations and non-profit organizations often orientate their programs towards accomplishing these goals.

- Content focus aims at disseminating "premium" and qualitative contents that are often demanded by Copyright by author(s); CC-BY 
relatively small audiences, but are important for enriching their opportunities to access non-commercial cultural programs. Publicly funded channels that aim at exposing audiences to cultural aspects, such as the trans-national Arte channel, mainly base their operational strategies on content focus (Stankiewicz, 2014).

Omrop Fryslân's management has diversified its audience to include radio and television target groups. Radio listeners are characterized by a relatively high level of loyalty towards their preferred radio stations, whereas the consumers of TV content present a lower degree of loyalty, and tend to zap between channels. However, in both these media channels, news and weather are the main attractors of audiences. Similar, customer preferences are visible in Omrop Fryslân's website, which show that the most popular page views are news coverage and weather reports.

Omrop Fryslân identified that its audience expands beyond the borders of the Dutch province, mainly to the US and Canada. It consists of immigrants who left the Netherlands in the post-World War II era and their offspring. Frisian-speaking Americans have a great interest in the happenings in their home province, and receive news updates via Omrop Fryslân's online broadcasts.

\section{CONCLUSIONS}

The Internet-based media that fosters the generation of the glocal dialog between the communities of immigrants and their homeland regions enriches, via free and widely available means of Internet transmissions, the different glocal media that immigrants use, such as local community newspapers and television stations, restaurants, and cinemas. The paper suggests that regional media stations unintentionally form a glocal bridgehead protecting immigrants' ties to their homeland regions, and more importantly strengthen the national and regional identity of the second and third generations, despite the often-described presumptions that these generations are likely to assimilate the local culture and language, and prefer it over their "glocal" links.

The paper offers new avenues for future research on the impact of local media on the glocal links of immigrants, including the use of social networks to form distant relations between immigrants and homeland inhabitants; the use of social networks (such as Instagram and Flickr) to retrieve local and regional sights of their homelands abroad; and the extent to which online media assist in fostering national and regional identities among immigrants.

Furthermore, the formation of glocal links may serve as a valuable channel for marketing homelandproduced goods. By advertising in local and regional channels that are known to be also used by communities of immigrants, homeland companies can target potential customers abroad in addition to their local markets. In addition, online broadcasting can serve as a valuable marketing tool for promotion of homeland-based services within communities of immigrants, such as heritage and family tours, and cultural events and festivals.

\section{AUTHOR INFORMATION}

Elad Harison, $\mathrm{PhD}$, is the Head of the Department of Industrial Engineering and Management at the Shenkar College of Engineering and Design, Ramat Gan, Israel. He specializes in the Economics of Innovation and technical change in the context of information technologies. He was involved in several research projects on innovation policies and ICT for the European Commission and for several European governments. E-mail: eladha@shenkar.ac.il

Ofer Barkai, $\mathrm{PhD}$, is a Senior Lecturer in the Department of Industrial and Management Engineering and Management at the Shamoon College of Engineering (SCE), Be'er Sheva, Israel. In addition, he has 27 years of industrial experience. He specializes in wage and compensation strategies at the organizational and managerial levels, compensation schemes, sectorial compensation and payment methods, and service organization. E-mail: ofer@sce.ac.il 


\section{REFERENCES}

Chan-Olmsted, S.M., \& Kan, J-W. (2003). Theorizing the strategic architecture of a broadband television industry. Journal of Media Economics.16(1), 3-21. DOI:10.1207/S15327736ME1601_2

Chan-Olmsted, S.M., \& Ha, L. (2003). Internet business models for broadcasters: how television stations perceive and integrate internet. Journal of Broadcasting \& Electronic Media,47(4), 597-616. DOI:10.1207/s15506878jobem4704_7

Chen P.G., Auerbach D.I., Muench U., Curry L.A., \& Bradley, E.H. (2013). Policy solutions to address the foreigneducated and foreign-born health care workforce in the United States. Health Affairs, 32(11), 1906-1913. DOI: $\underline{10.1377 / \text { hlthaff.2013.0576 }}$

Docquier F., Rapoport H., \& Salomone S. (2012) Remittances, migrants' education and immigration policy: Theory and evidence from bilateral data. Regional Science and Urban Economics, 42(5), 817-828. DOI: 10.1016/j.regsciurbeco.2011.10.005

Doyle, G. (2010) From television to multi-platform: less from more or more for less? Convergence, 16(4), 431-449. DOI: $\underline{10.1177 / 1354856510375145}$

Elias N., \& Lemish D. (2011). Between three worlds: host, homeland, and global media in the lives of Russian immigrant families in Israel and Germany. Journal of Family Issues, 32(9), 1245-1274. DOI: 10.1177/0192513X11400837

Elias N. (2013). Immigrants' internet use and identity from an intergenerational perspective: Immigrant senior citizens and youngsters, In Luppicini R. (ed.), Handbook of research on technoself: Identity in a technological society, IGI Global. DOI: 10.4018/978-1-4666-2211-1.ch016

Hofstede, G. (1994). Management scientists are human. Management Science, 40(1), 4-13. DOI: $10.1287 / \mathrm{mnsc} .40 .1 .4$

Leung, L. (2004). Net-generation attributes and seductive properties of the internet as predictors of online activities and internet addiction. CyberPsychology \& Behaviour, 7(3), 333-348. DOI: $10.1089 / 1094931041291303$

Lin, C. (2008). Technology fluidity and on-demand webcasting adoption. Telematics and Informatics, 25(2), 84-98. DOI: $10.1016 / \mathrm{j}$. tele.2006.06.002

Loebbecke, C., Powell, P., \& Trillingh, S. (1998). Investigating the worth of Internet advertising. International Journal of Information Management, 18(3), 181-193. DOI: 10.1016/S0268-4012(98)00003-6

Merton, R.K. (1938). Social Structure and Anomie. American Sociological Review, 3(5), 37-45.

Rusciano, F.L. (2014) "Surfing Alone": The Relationships among Internet Communities, Public Opinion, Anomie, and Civic Participation. Studies in Sociology of Science, 5(3), 37-44.

Soehl T., \& Waldinger R. (2012). Inheriting the homeland? Intergenerational transmission of cross-border ties in migrant families. American Journal of Sociology, 118(3), 778-813. DOI: $10.1086 / 667720$

Stankiewicz, D. (2014). Regathering the imagined audience: shifting strategies at a trans-European public television channel. Television \& New Media, 15(5): 487-503. DOI: $10.1177 / 1527476412461056$

Toivanen M., \& Kivisto P. (2014). Homing desire at the juncture of place and transnational spaces: The case of young Kurds in Finland. Nordic Journal of Migration Research, 4(2), 65-72. DOI: 10.2478/njmr-2014$\underline{0011}$

Yan, M.C., Lam C.M., \& Lauer S. (2014). Return migrant or diaspora: An exploratory study of new-generation Chinese-Canadian youth working in Hong Kong. Journal of International Migration and Integration, 15(2), 179-196. DOI: 10.1007/s12134-013-0274-8

Zhou, M., \& Cai, G. (2002). Chinese language media in the United States: immigration and assimilation in American life. Qualitative Sociology, 25(3), 419-441. DOI: 10.1023/A:1016090131463 